\title{
Study on proportioning of similar materials for overburden rock in underground gasification model experiment
}

\author{
Lin Xin ${ }^{\mathrm{a}, \mathrm{b}^{*}}$, Limin $\mathrm{Han}^{\mathrm{b}}$, Mingyu $\mathrm{An}^{\mathrm{b}}$, Jian $\mathrm{Li}^{\mathrm{b}}$, Chao $\mathrm{Li}^{\mathrm{b}}$, Min $\mathrm{Xu}^{\mathrm{b}}$, Mingze Feng ${ }^{\mathrm{b}}$, and \\ Kaixuan $\mathrm{Li}^{\mathrm{b}}$ \\ ${ }^{a}$ Key Laboratory of Ministry of Education for Mine Disaster Prevention and Control, Shandong \\ University of Science and Technology, Qingdao, Shandong 266590, China; \\ ${ }^{\mathrm{b}}$ College of Safety and Environmental Engineering, Shandong University of Science and Technology, \\ Qingdao, Shandong 266590, China
}

\begin{abstract}
In order to provide an accurate theoretical basis for the underground gasification model test of coal, the similar materials ratio of underground gasification's overburden rock was studied by orthogonal experiment according to the similarity theory. The results show: the fifth group material ratio meets the model test requirements, the mass ratio of sand, cement and gypsum is $6: 1: 1$, and the compressive strength is $1.36 \mathrm{MPa}$; the material strength is most sensitive to sand as compared to cement and gypsum; the compressive strength decreases as the aggregate-binder ratio increases. When the aggregate-binder ratio remains the same, the compressive strength decreases as the cement-gypsum ratio increases; the compressive strength-elastic modulus curve of the specimen increases linearly and conforms to the sandstone fitting curve in the coal-bearing strata; the failure mode of similar materials is mainly shear failure.
\end{abstract}

\section{Introduction}

Underground Coal Gasification (UCG) converts coal in situ (underground) into gaseous products by the same chemical reactions that occur in conventional gasification plants, commonly referred to as syngas or syngas [1-14]. UCG applies to Waste coal, non-minable coal seams, and deep coal seams in mined coal seams or traditional mining methods, and it can increase recoverable coal reserves [1, 7-9]. It has the advantages of low gas production cost, high safety and good environmental benefits, which will reduce greenhouse gas emissions [1, 6, 7].

As a clean coal technology, UCG has been discussed and experimented for more than 100 years and has received worldwide attention and has been used in many pilot locations, including the former Soviet Union, the United States, Europe, Australia, China, Japan, India, etc. $[4,6,7,15]$. In recent years, a large number of theoretical and experimental studies have been conducted in the UCG process to study the effects of various gasification

\footnotetext{
* Corresponding author: xinlinsdust@sdust.edu.cn
} 
operating parameters $[9,10,15-20]$. Among them, the study of various gasification operating parameters through model tests has become an effective method for underground coal gasification research [10, 18-20]. However, choosing the right simulation material and ratio is very important for the results of similar model experiments [21-23].

At present, researchers in various fields have done a lot of research work in the field of similar material matching research [21-26], and achieved good engineering results. Among them, Cheng et al. [22] determined the proportion of steeply inclined extra-thick coal seams by similar material ratio experiments, and used model tests to explore the movement of surrounding rock and the development of fissures; Liu [26] determined the similar material ratio of underground gasification roof rock according to the similarity theory, and discussed the expansion of the combustion zone and the stability of the roof; based on the similarity principle, Xi et al. [24] determined the material ratio of the roof rock of coal underground gasification coal seam by orthogonal experiment.. The above research results have important guiding significance for the similar material ratio research of underground gasification model coal seam overlying rock.

Based on the previous research results, this paper took the sandstone roof of No. 9 coal seam in Yuanbao Coal Mine of Youyu, Shanxi Province as the research object, and conducted a similar material ratio study. Based on the similarity theory, this experiment mainly conducts mechanical similarity studies. With sand as the aggregate, cement and gypsum as the cementing agent, material pairing orthogonal testing were carried out, and the uniaxial compression test was carried out. The material ratios satisfying the requirements of the overburden mechanics of the underground gasification model were selected. Provide theoretical guidance for the future coal seam underground coal gasification model test in this area, and improve the reliability of the coal underground gasification model test results.

\section{Experiment}

\subsection{Experimental method}

The model test similarity principle refers to the reproduction of physical phenomena and physical parameters of the prototype on the model, such as the shape and size of the model and the prototype follow a certain law $[24,26]$. Among them, the ratio of the physical parameters (having the same dimension) of the prototype (') and the model (") is called a similarity constant, and is represented by a capital letter C. The UCG model experiment is to select similar materials to make a similar coal seam and rock formation model, ignite the coal seam, simulate the underground gasification process, and collect data during the gasification process, such as temperature change, gas production, and the movement and deformation and destruction of surrounding rock. In this way, the process in the actual underground coal gasification is inferred.

In a similar system of geometry and elasticity, the thermodynamic similarity is obtained by similar temperature and heat fields. Write the heat conduction differential equation and the single-valued condition of the surrounding rock of the gasification channel and the deformation control equation of the surrounding rock.

The thermal differential equation is:

$$
\frac{\partial T}{\partial t}=\alpha\left(\frac{\partial^{2} T}{\partial x^{2}}+\frac{\partial^{2} T}{\partial y^{2}}+\frac{\partial^{2} T}{\partial z^{2}}\right)
$$

Initial conditions: $\left.T(x, y, z, t)\right|_{t=0}=T_{0}$ 
Boundary conditions are as follows:

$$
\left\{\begin{array}{l}
\left.T(x, t)\right|_{x=x_{1}}=T_{1} \\
\left.\lambda \frac{\partial T}{\partial n}\right|_{x=x_{1}}=h\left(T_{w}-T_{f}\right), t>0 \\
\left.\frac{\partial T}{\partial n}\right|_{x \rightarrow \infty}=0
\end{array}\right.
$$

Surrounding rock deformation control equations [26] are as follows:

$$
\left\{\begin{array}{l}
(\kappa+G) \frac{\partial \varepsilon}{\partial x}+G \nabla^{2} u+X-\frac{E a}{1-2 \mu} \frac{\partial T}{\partial x}=0 \\
(\kappa+G) \frac{\partial \varepsilon}{\partial y}+G \nabla^{2} v+Y-\frac{E a}{1-2 \mu} \frac{\partial T}{\partial y}=0 \\
(\kappa+G) \frac{\partial \varepsilon}{\partial z}+G \nabla^{2} w+Z-\frac{E a}{1-2 \mu} \frac{\partial T}{\partial z}=0
\end{array}\right.
$$

Here, $\alpha=\lambda / \rho \mathrm{Cp}$ is the thermal diffusivity (conductivity coefficient), $\left(\mathrm{m}^{2} / \mathrm{s}\right)$, which reflects the relationship between, he thermal conductivity $(\lambda)$ of the material during heat conduction and the heat storage capacity $(\rho \mathrm{Cp})$ of the material; $T$, is the tempe rature, $\mathrm{K}$; $\mathrm{t}$, is the time, $\mathrm{s} ; \mathrm{x}, \mathrm{y}, \mathrm{z}$, are the displacement, $\mathrm{m} ; \mathrm{\kappa}$ is the Lame constant; $\mathrm{G}$ is the shear modulus; $\mathcal{E}$ is the volumetric strain;

$$
\nabla^{2} \mathrm{u}=\frac{\partial^{2} u}{\partial x^{2}}+\frac{\partial^{2} u}{\partial y^{2}}+\frac{\partial^{2} u}{\partial z^{2}}
$$

is the Laplacian; $\mathrm{u}, \mathrm{v}, \mathrm{w}$ are the elastic displacement; $\mathrm{X}, \mathrm{Y}, \mathrm{Z}$ are the volumetric force; $\mathrm{E}$ is the elastic modulus; $a$ is the thermal expansion coefficient; and $\mu$ is the Poisson's ratio.

The similar constants used are as follows:

$$
\begin{aligned}
& \frac{T^{\prime}}{T^{\prime \prime}}=C_{T}, \frac{t^{\prime}}{t^{\prime \prime}}=C_{t}, \frac{\alpha^{\prime}}{\alpha^{\prime \prime}}=C_{\alpha}, \frac{\lambda^{\prime}}{\lambda^{\prime \prime}}=C_{\lambda}, \frac{\kappa^{\prime}}{\kappa^{\prime \prime}}=C_{\kappa}, \frac{G^{\prime}}{G^{\prime \prime}}=C_{G}, \frac{E^{\prime}}{E^{\prime \prime}}=C_{E}, \\
& \frac{\varepsilon^{\prime}}{\varepsilon^{\prime \prime}}=C_{\varepsilon}, \frac{\mu^{\prime}}{\mu^{\prime \prime}}=C_{\mu}, \frac{x^{\prime}}{x^{\prime \prime}}=C_{l}, \frac{a^{\prime}}{a^{\prime \prime}}=C_{a}, \frac{X^{\prime}}{X^{\prime \prime}}=C_{\gamma}, \frac{u^{\prime}}{u^{\prime \prime}}=C_{u}, \frac{T^{\prime}}{T^{\prime \prime}}=C_{T}, \\
& \frac{x^{\prime}}{x^{\prime \prime}}=\frac{y^{\prime}}{y^{\prime \prime}}=\frac{z^{\prime}}{z^{\prime \prime}}=C_{l}
\end{aligned}
$$

Simultaneously,

$$
\frac{\partial \varepsilon^{\prime}}{\partial x^{\prime}}=\frac{C_{\varepsilon}}{C_{l}} \frac{\partial \varepsilon^{\prime \prime}}{\partial x^{\prime \prime}}, \quad \nabla^{2} u^{\prime}=\frac{C_{u}}{C_{l}^{2}} \nabla^{2} u^{\prime \prime}
$$


The above relationships are taken into the heat conduction differential equation and the surrounding rock deformation control equation (the first item of the control equation is selected as an example), and the results are obtained separately:

$$
\begin{gathered}
\frac{C_{T}}{C_{t}} \frac{\partial T^{\prime \prime}}{\partial t^{\prime \prime}}=\frac{C_{\alpha} C_{T}}{C_{l}^{2}} \alpha^{\prime \prime}\left(\frac{\partial^{2} T^{\prime \prime}}{\partial x^{22}}+\frac{\partial^{2} T^{\prime \prime}}{\partial y^{2}}+\frac{\partial^{2} T^{\prime \prime}}{\partial z^{\prime 2}}\right) \\
\frac{C_{\kappa} C_{\varepsilon}}{C_{l}} \kappa^{\prime \prime} \frac{\partial \varepsilon^{\prime \prime}}{\partial x^{\prime \prime}}+\frac{C_{G} C_{\varepsilon}}{C_{l}} G^{\prime \prime} \frac{\partial \varepsilon^{\prime \prime}}{\partial x^{\prime \prime}}+\frac{C_{G} C_{u}}{C_{l}^{2}} G^{\prime \prime} \nabla^{2} u^{\prime \prime}+C_{\gamma} X^{\prime \prime}-\frac{C_{E} C_{a} C_{T}}{C_{l}} \frac{E^{\prime \prime} a^{\prime \prime}}{1-2 C_{\mu} \mu^{\prime \prime}} \frac{\partial T^{\prime \prime}}{\partial x^{\prime \prime}}=0
\end{gathered}
$$

Compare the coefficients of the above equation with the coefficients in the model. If the above equation is true, you can get:

$$
\begin{gathered}
\frac{C_{T}}{C_{t}}=\frac{C_{\alpha} C_{T}}{C_{l}^{2}} \\
\frac{C_{\kappa} C_{\varepsilon}}{C_{l}}=\frac{C_{G} C_{\varepsilon}}{C_{l}}=\frac{C_{G} C_{u}}{C_{l}^{2}}=C_{\gamma}=\frac{C_{E} C_{a} C_{T}}{C_{l}} \\
C_{\mu}=1
\end{gathered}
$$

Discuss the relationship between the equations separately, and derive the Similarity criterion from this, see Table 1.

Table 1. Similarity criterion

\begin{tabular}{ll}
\hline Similarity criterion & Remarks \\
\hline$C_{\varepsilon}=1$ & Strain similarity \\
\hline$C_{\sigma}=C_{\gamma} C_{l}$ & Strength similarity \\
\hline$C_{a} C_{T}=1$ & Temperature field is similar \\
\hline$C_{\alpha} C_{t}=C_{l}^{2}$ & Time similarity \\
\hline
\end{tabular}

\subsection{Experimental materials and apparatus}

(1) Experimental materials

The experimental prototype of this underground gasification model is No. 9 coal seam of Shanxi Youyu Yuanbao Coal Mine. The research object is medium sandstone at the top of No. 9 coal seam. The average thickness of coal seam is $14.33 \mathrm{~m}$, and the burning length is $80 \mathrm{~m}$. Limited by the size of the laboratory model experimental platform, the geometrical similarity constant of the selected model experiment is 30 . The compressive strength and density of the medium sandstone are $68.03 \mathrm{MPa}$ and $2600 \mathrm{~kg} / \mathrm{m}^{3}$, respectively. 
Choosing the right simulation material and ratio is very important for the results of similar model experiments[21-23]. The basis for selecting similar materials is that the mechanical index is stable and does not change due to the influence of temperature and humidity; after changing the ratio, it can make the mechanical index have a large change range, so as to be easy to select and use; the production is convenient, and the solidification time is short, low cost. Therefore, the aggregate was made of sand, and the cement was made of cement and gypsum. Among them, gypsum solidifies quickly, can make similar materials quickly form and increase strength; and cement has high strength, which can increase the strength of similar materials [27].

(2) Experimental apparatus

Hydraulic press (see Fig. 1 (a)), mold (see Fig. 1 (b)), Shimadzu AGX-250 electronic universal tester (see Fig. 1 (c)).

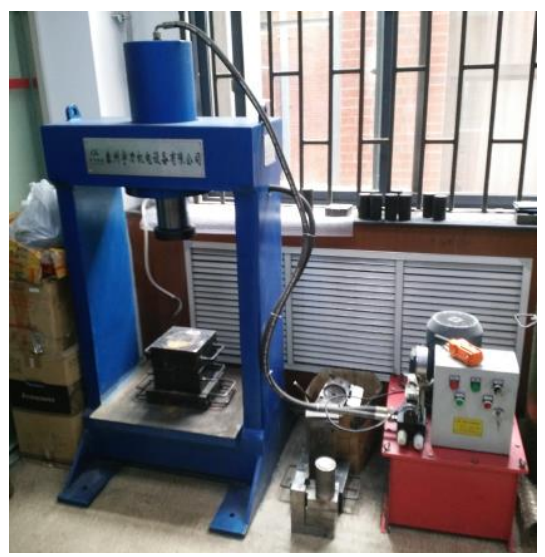

(a)

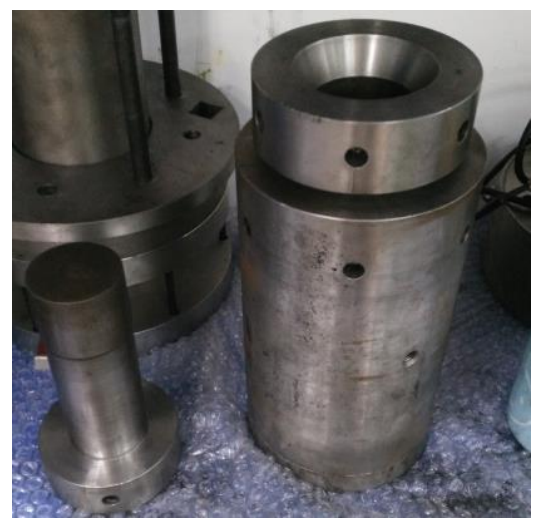

(b) 


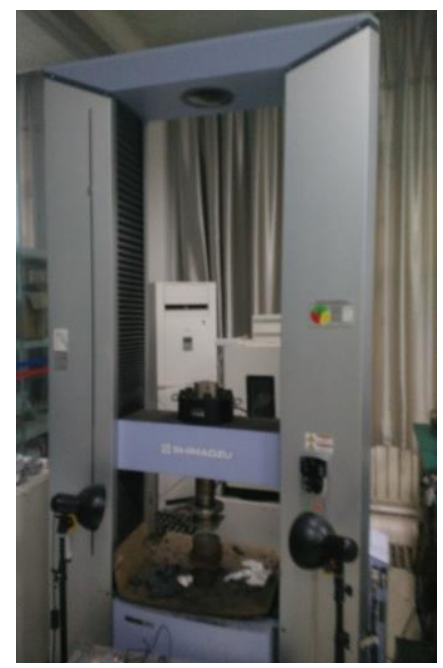

(c)

Fig. 1. Experimental equipment

\subsection{Experimental design}

(1) The purpose of this design scheme is to obtain the main factors and proportion range that can affect the compressive strength of similar materials by orthogonal test method, and choose the ratio that meets the mechanical requirements of the top coal seam of the model experiment.

(2) This orthogonal test design scheme used sand (aggregate), cement and gypsum (cement) as the three factors of orthogonal design, the fourth element was empty, and each factor was set to 4 levels, see Table 2.

Table 2. Similar material factor level table

\begin{tabular}{lllll}
\hline $\begin{array}{l}\text { Proportion } \\
\text { number }\end{array}$ & Sand & Cement & Gypsum & $\begin{array}{l}\text { Empty } \\
\text { column }\end{array}$ \\
\hline 1 & 3 & 1 & 0.5 & 1 \\
\hline 2 & 6 & 1.5 & 1 & 2 \\
\hline 3 & 9 & 2 & 1.5 & 3 \\
\hline 4 & 12 & 2.5 & 2 & 4 \\
\hline
\end{tabular}

3) The orthogonal design scheme of this orthogonal experiment selected the orthogonal design table of 4 factors and 4 levels, see Table 3.

Table 3. Orthogonal experiment design table

\begin{tabular}{ccccc}
\hline $\begin{array}{c}\text { Proportion } \\
\text { number }\end{array}$ & Sand & Cement & Gypsum & Empty column \\
\hline 1 & 3 & 1 & 0.5 & 1 \\
\hline
\end{tabular}




\begin{tabular}{ccccc}
\hline $\begin{array}{c}\text { Proportion } \\
\text { number }\end{array}$ & Sand & Cement & Gypsum & Empty column \\
\hline 2 & 3 & 1.5 & 1 & 2 \\
\hline 3 & 3 & 2 & 1.5 & 3 \\
\hline 4 & 3 & 2.5 & 2 & 4 \\
\hline 5 & 6 & 1 & 1 & 3 \\
\hline 6 & 6 & 1.5 & 0.5 & 4 \\
\hline 7 & 6 & 2 & 2 & 1 \\
\hline 8 & 6 & 2.5 & 1.5 & 2 \\
\hline 9 & 9 & 1 & 1.5 & 4 \\
\hline 10 & 9 & 1.5 & 2 & 3 \\
\hline 11 & 9 & 2 & 0.5 & 2 \\
\hline 12 & 9 & 2.5 & 1 & 2 \\
\hline 13 & 12 & 1 & 2 & 1 \\
\hline 14 & 12 & 1.5 & 1.5 & 4 \\
\hline 15 & 12 & 2 & 1 & 3 \\
\hline 16 & 12 & 2.5 & 0.5 & \\
\hline
\end{tabular}

The figures in the columns of sand, cement and gypsum in the table are the mass ratio between them.

\subsection{Experimental procedure}

First, we made 16 sets of standard specimens of $\Phi 50 \mathrm{~mm} \times 100 \mathrm{~mm}$ with one mold, and prepared three specimens for each set of experiments. Mix the sand, cement and gypsum according to the proportion of Table 3, the ratio of water and ingredients is 1:11, stir evenly, pour into the mold, cover the lid, place the mold on the hydraulic press, pressurize the specimen, and maintain the pressure for 15 minutes. After the pressure holding process is completed, the mold is taken out of the hydraulic press, the mold is taken out, the pressed specimen is taken out, and the label is attached. The test piece was dried indoors for 7 days (as shown in Fig. 2), the weight and height were measured, the material density was calculated, and the ideal model compressive strength of the different groups was calculated, as shown in Table 4. 


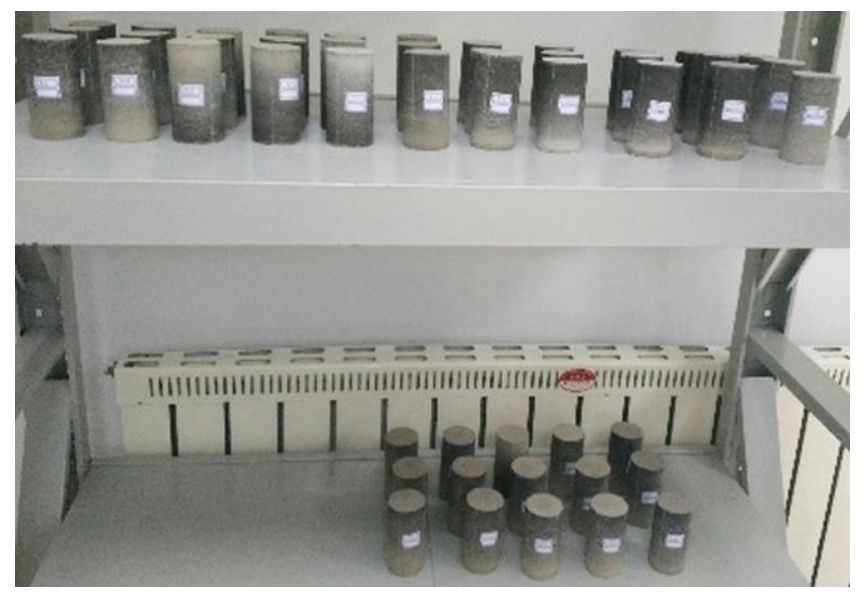

Fig. 2. 16 sets of specimens

Table 4. Ideal similar material parameter

\begin{tabular}{ccccc}
\hline $\begin{array}{c}\text { Proportion } \\
\text { number }\end{array}$ & $\mathbf{C}_{\gamma}$ & $\mathbf{C}_{\mathbf{l}}$ & $\begin{array}{c}\text { Ideal model } \\
\text { compressive strength } \\
\text { /MPa }\end{array}$ & $\begin{array}{c}\text { Prototype } \\
\text { compressive } \\
\text { strength /MPa }\end{array}$ \\
\hline 1 & 1.75 & 30 & 1.30 & 68.03 \\
\hline 2 & 1.64 & 30 & 1.38 & 68.03 \\
\hline 3 & 1.64 & 30 & 1.38 & 68.03 \\
\hline 4 & 1.66 & 30 & 1.37 & 68.03 \\
\hline 5 & 1.67 & 30 & 1.36 & 68.03 \\
\hline 6 & 1.67 & 30 & 1.36 & 68.03 \\
\hline 7 & 1.64 & 30 & 1.38 & 68.03 \\
\hline 8 & 1.65 & 30 & 1.38 & 68.03 \\
\hline 9 & 1.68 & 30 & 1.35 & 68.03 \\
\hline 10 & 1.69 & 30 & 1.34 & 68.03 \\
\hline 11 & 1.69 & 30 & 1.34 & 68.03 \\
\hline 12 & 1.68 & 30 & 1.35 & 68.03 \\
\hline 13 & 1.70 & 30 & 1.34 & 68.03 \\
\hline 14 & 1.70 & 30 & 1.34 & 63.03 \\
\hline 15 & 1.71 & 30 & 1.33 & 1.32 \\
\hline 16 & 1.71 & 30 & & \\
\hline
\end{tabular}

\section{Results and discussion}




\subsection{Compressive strength analysis of similar materials}

The compressive strength and elastic modulus of the test piece were calculated based on the data, as shown in Table 5.

Table 5. compressive strength and elastic modulus of the test piece

\begin{tabular}{|c|c|c|}
\hline $\begin{array}{l}\text { Proportion } \\
\text { number }\end{array}$ & $\begin{array}{l}\text { Compressive } \\
\text { strength/MPa }\end{array}$ & $\begin{array}{c}\text { Elastic } \\
\text { modulus/GPa }\end{array}$ \\
\hline 1 & 1.2 & 0.14 \\
\hline 2 & 3.43 & 0.35 \\
\hline 3 & 3.26 & 0.4 \\
\hline 4 & 4.25 & 0.5 \\
\hline 5 & 1.43 & 0.15 \\
\hline 6 & 1.15 & 0.1 \\
\hline 7 & 2.48 & 0.29 \\
\hline 8 & 2.49 & 0.25 \\
\hline 9 & 1.55 & 0.16 \\
\hline 10 & 1.59 & 0.22 \\
\hline 11 & 1.18 & 0.09 \\
\hline 12 & 1.52 & 0.14 \\
\hline 13 & 1.26 & 0.12 \\
\hline 14 & 1.21 & 0.12 \\
\hline 15 & 1.19 & 0.1 \\
\hline 16 & 0.97 & 0.09 \\
\hline
\end{tabular}

According to Table 4 and Table 5, the compressive strength parameters of the similar materials in the simulation experiment are in the range of $1.30 \mathrm{MPa}-1.38 \mathrm{MPa}$; the actual measured compressive strength is between $0.97 \mathrm{MPa}$ and $4.25 \mathrm{MPa}$.

If the measured pressure data for a certain set of specimens is equal to or close to the calculated ideal pressure data, then the similar material ratio for the set can be considered to meet the requirements of the simulation experiment. The actual measurement data and ideal calculation data are shown in Fig. 3. 


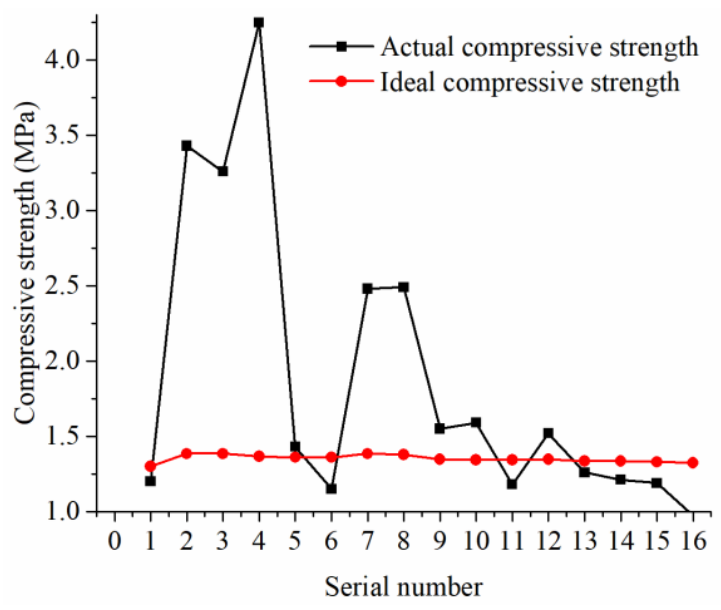

Fig. 3. Comparison of ideal and measured values of compressive strength of different groups

According to Fig. 3, the strength of the fifth group of specimens in Table 5 is $1.43 \mathrm{MPa}$, which is the closest to the fifth group of $1.36 \mathrm{MPa}$ in Table 4 . Therefore, the fifth group of similar materials meets the theoretical requirements. It can be applied to underground coal gasification simulation experiments. The mass ratio of similar materials in the fifth group is sand: cement: gypsum $=6: 1: 1$.

\subsection{Analysis of factors affecting compressive strength of similar materials}

\subsubsection{Sensitivity analysis of various factors of similar materials}

For each factor affecting the compressive strength, the range is calculated as shown in Table 6.

Table 6. Range of factors

\begin{tabular}{lllll}
\hline & Sand & Cement & Gypsum & Empty column \\
\hline $\mathrm{k} 1$ & 3.04 & 1.00 & 1.13 & 1.61 \\
$\mathrm{k} 2$ & 1.89 & 1.85 & 1.90 & 2.09 \\
$\mathrm{k} 3$ & 1.46 & 2.03 & 2.13 & 1.81 \\
$\mathrm{k} 4$ & 1.16 & 2.31 & 2.40 & 2.04 \\
Range & 1.88 & 1.31 & 1.27 & 0.49 \\
\hline
\end{tabular}

The error of sand, cement, gypsum and empty row is $1.88,1.31,1.27,0.49$, which indicates that the strength of the material is most sensitive to sand, and the sensitivity to cement and gypsum is small. The sand, cement and gypsum materials are negligible interaction.

\subsubsection{Relationship between compressive strength of similar materials and various factors}


The influence of various factors on the compressive strength of the test piece, as shown in Fig. 4.
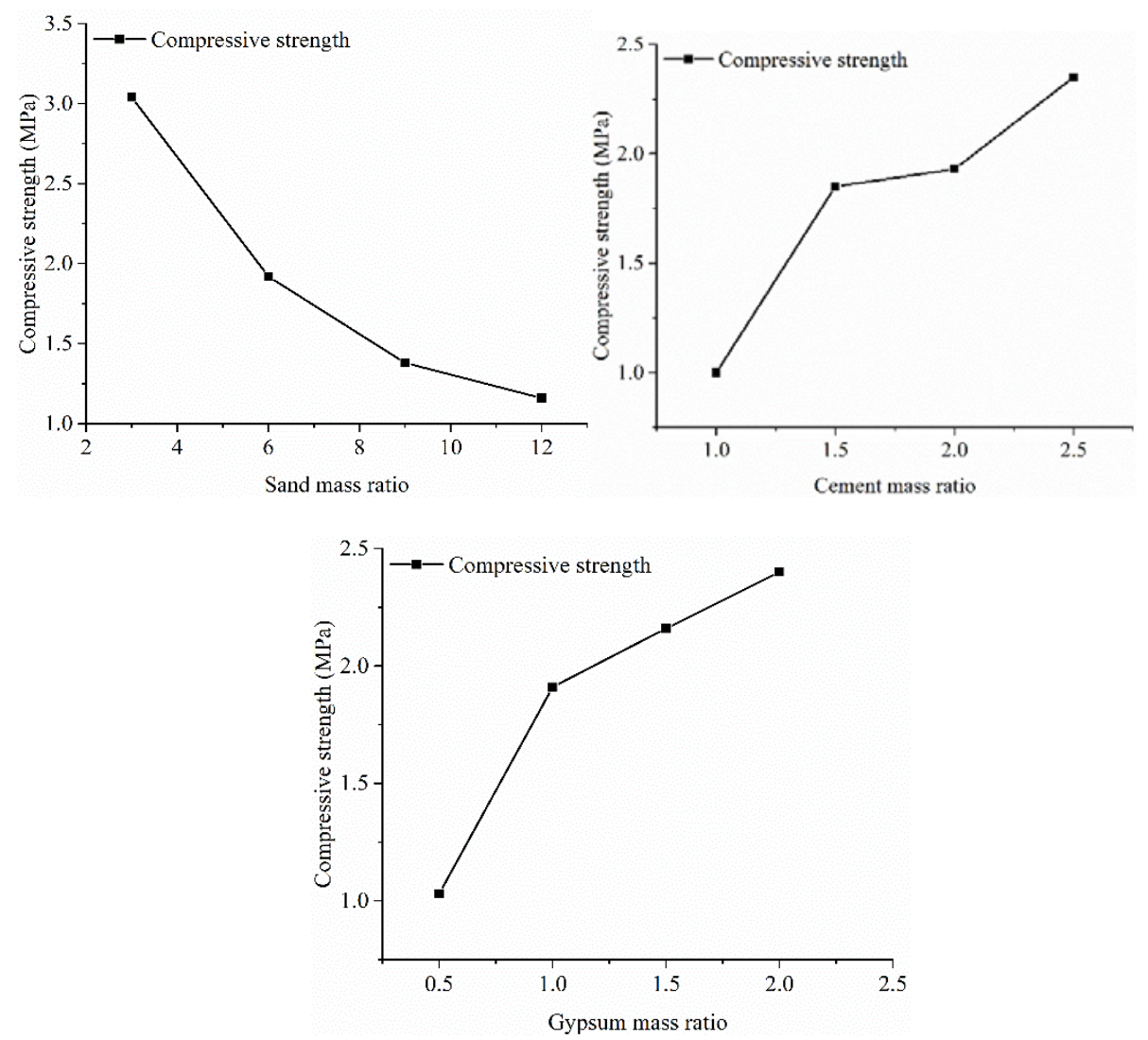

Fig. 4. Analysis of orthorhombic factors on uniaxial compressive strength

According to analysis of orthorhombic factors on uniaxial compressive strength, the influence of various factors on the compressive strength parameters of similar materials can be directly observed. It can be obtained from Fig. 4 that the compressive strength of the material is inversely proportional to the mass ratio of the sand, and is proportional to the mass ratio of cement and gypsum. Due to the small particle size and particle size of cement and gypsum cement, the solidification effect of cement and gypsum, the porosity of similar materials is small, dense, and the compressive strength is increased. At the same time, the specific gravity of the sand increases, the specific gravity of the cement decreases, and the compressive strength, the intensity is reduced [24].

\subsubsection{Relationship between compressive strength of similar materials and aggregate-binder ratio}

The relationship curve between the uniaxial compressive strength and aggregate-binder ratio is shown in Fig. 5. 


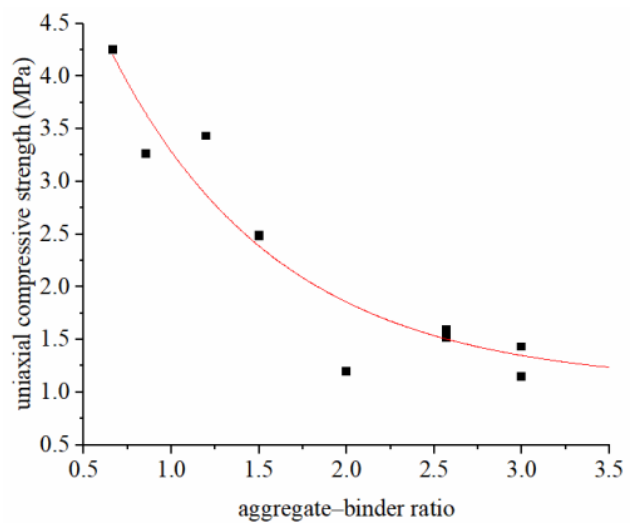

Fig. 5. Relationship curve between uniaxial compressive strength and aggregate-binder ratio

Fig. 5 shows that the compressive strength of the test piece decreases as the aggregate-binder ratio increases, and the descending speed gradually decreases.

2.2.4. Relationship between compressive strength of similar materials and cement-gypsum ratio

Fig. 6 is the relationship between the ratio of cement to gypsum and the uniaxial compressive strength when the aggregate-binder ratio is constant. The cement-gypsum ratio at this time is 4 . The uniaxial compressive strength decreases as the cement-gypsum ratio increases.

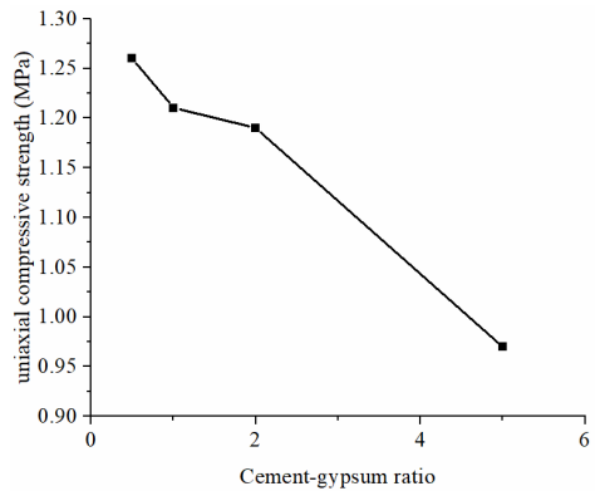

Fig. 6. Relationship curve between uniaxial compressive strength and cement-gypsum ratio 


\subsection{Analysis of specimen failure process}

\subsubsection{Specimens e failure characteristics}

A total of 48 rock specimens were tested. combined with the sampling situation, 8 representative rock specimens were selected for analysis.

Fig. 7 is a photograph of a uniaxial failure of a specimen. As can be seen from the photograph, the end face of the specimen passes through the crack and has a distinct rupture surface. The rupture surface is at an angle to the central axis of the test piece. The workpiece is divided into cones or triangles, indicating that the specimen is shear-damaged and shear-damaged is dominant during uniaxial compression. There is a relatively large block at both ends of the specimen, which is caused by the terminal friction effect $[28,29]$.

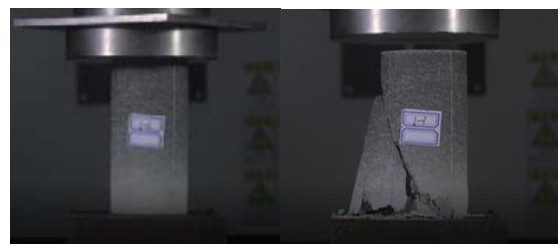

Specimen 1-1

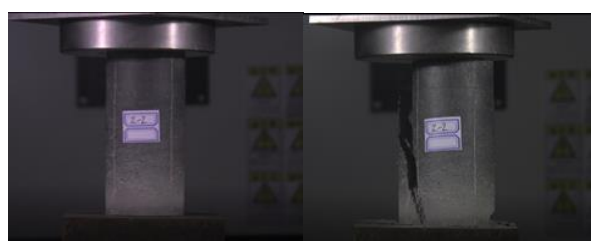

Specimen 2-2

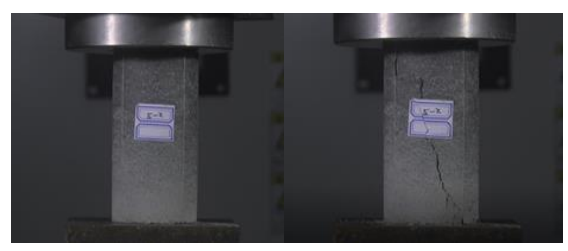

Specimen 5-2

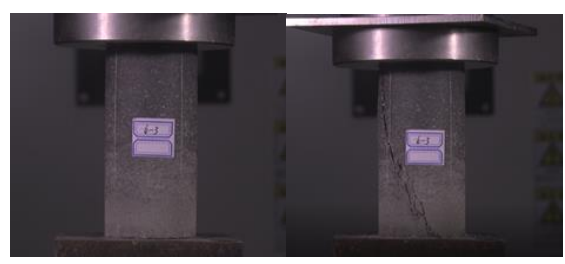

Specimen 6-3

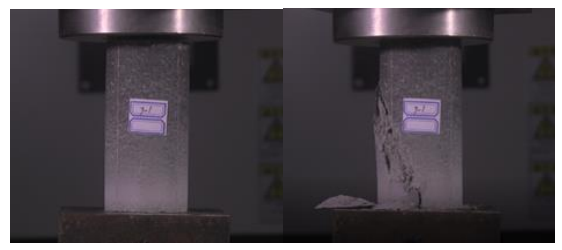

Specimen 7-1

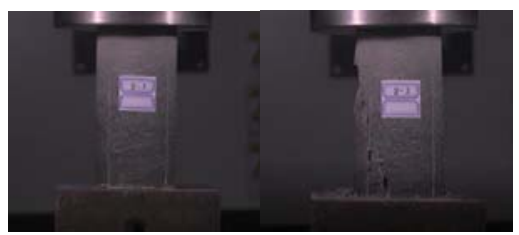

Specimen 8-3

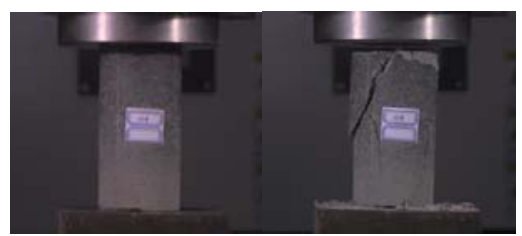

Specimen 11-1

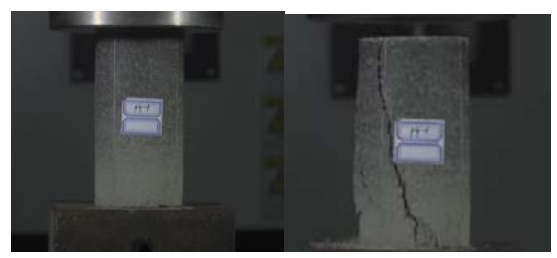

Specimen 15-1

Fig. 7. Single-axis compression damage photo of the specimens 


\subsubsection{Stress-strain curve}

The stress-strain curve of the uniaxial compression process of the test piece is shown in Fig. 8 .
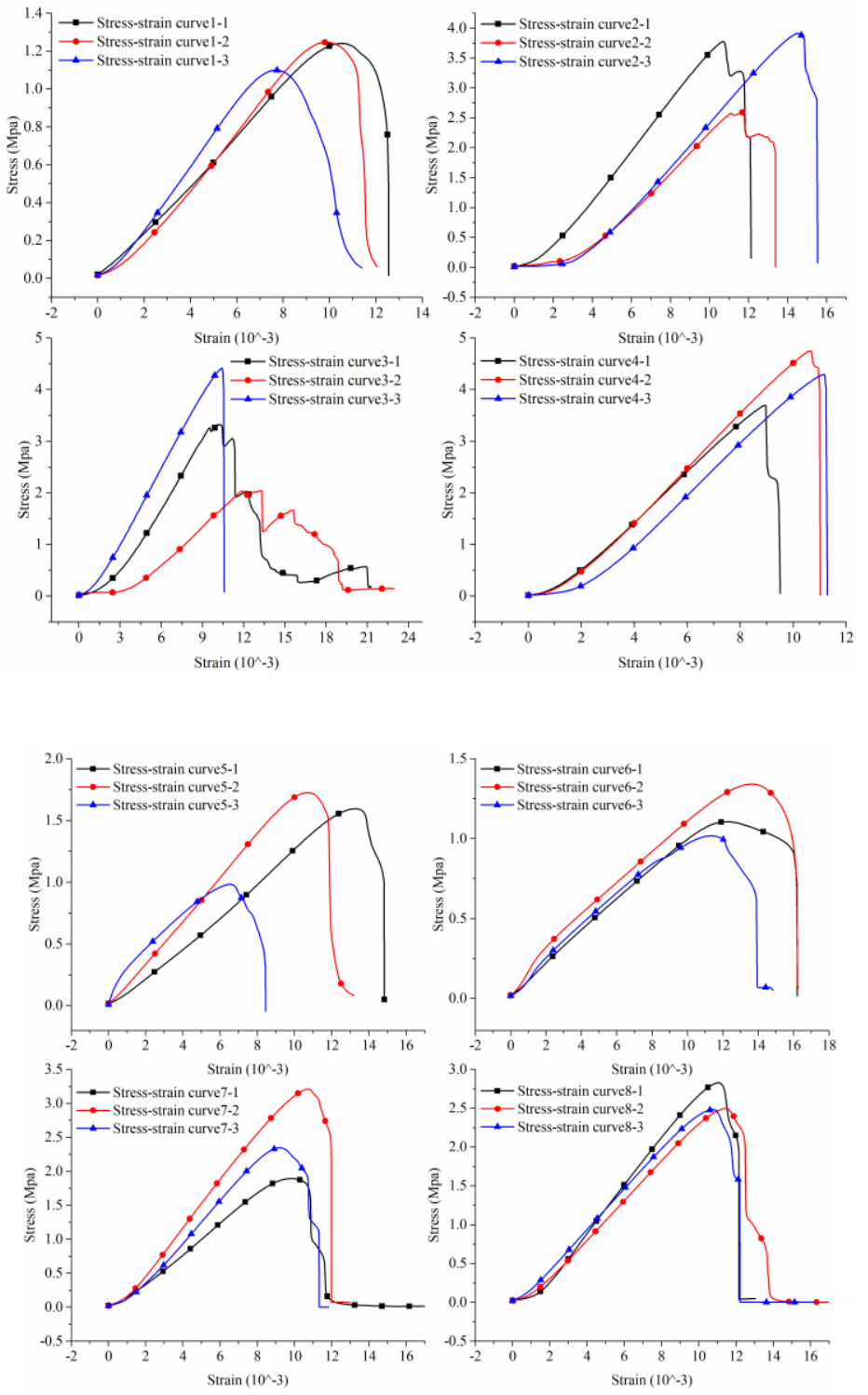

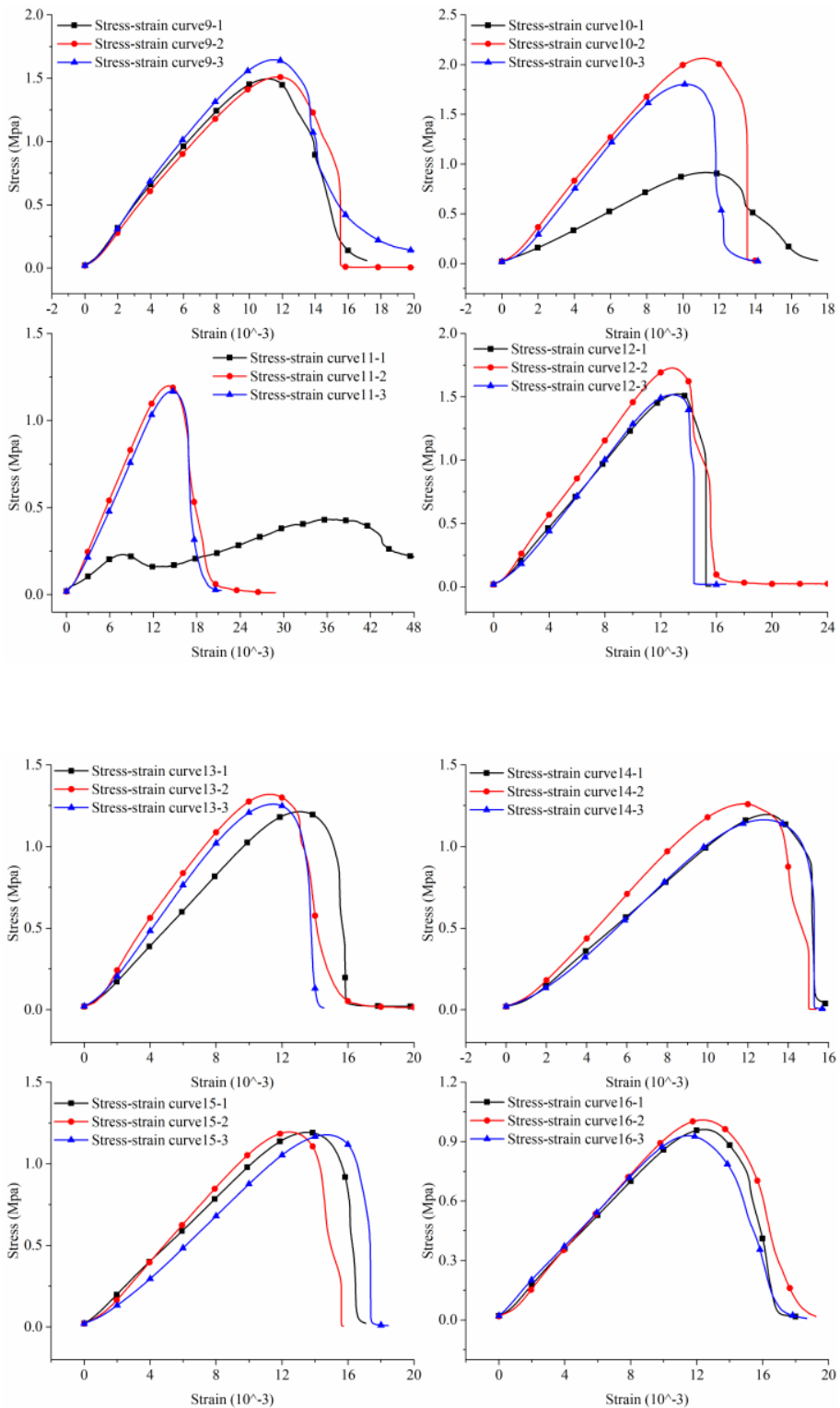

Fig. 8. Stress-strain curve of the test piece

It can be seen from Fig. 8 that the variation of the stress-strain curve of the specimens with different similar materials generally goes through four stages [30, 31]:

(1) During the pore compaction stage, the crack of the test piece is gradually closed, the rock is compacted, and nonlinear deformation is formed, and the curve is concave.

(2) In the elastic deformation stage, the curve approximates a linear relationship, and the deformation increases proportionally with the stress. 
(3) In the rupture stage, a new micro-fracture starts to be produced inside the test piece, and gradually develops as the stress increases, and the curve bends away from the straight line toward the longitudinal axis. The carrying capacity of the test piece is maximized.

(4) After the failure stage, after the bearing capacity reaches the peak value, the internal structure is completely destroyed, but the test piece is basically kept intact, and the crack develops rapidly, forming a macroscopic fracture surface, as shown in Fig. 7.After that, the deformation of the test piece mainly showed that the block along the macro-fracture surface slipped, and the bearing capacity of the test piece decreased rapidly with the increase of the deformation.

The difference in stress-strain curves in specimens 3, 5, 10 and 11 is obviously too large and should be caused by the erroneous operation of the test piece during the manufacturing process, so curves 3-2, 5-3, 10-1, 11-1 Should not be included in the analysis.

\subsubsection{Relationship between elastic modulus and compressive strength}

Analyze the relationship between the compressive strength of the test piece and the elastic modulus, as shown in Fig. 9.

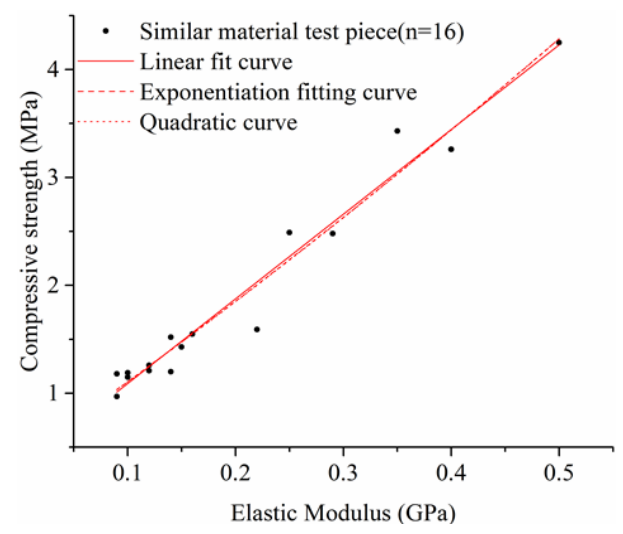

Fig. 9. Relationship between elastic modulus and compressive strength of specimens

By linearly fitting the test piece data, exponential fitting and quadratic fitting, the relationship between compressive strength and elastic modulus of the test piece can be obtained, as shown in Fig. 9. It is linear, and consistent with the fitted curve of sandstone in coal-bearing strata [32].

\section{Conclusions}

Based on the similarity theory, this paper studies the similar materials of underground gasification roof sandstone by orthogonal experiment and draws the following conclusions:

(1) The object of this study is the overburden rock of No. 9 coal seam roof, and its main lithology is medium sandstone. The experimental results show that the compressive strength of specimen range is $0.97 \mathrm{MPa}-4.25 \mathrm{MPa}$, which is widely distributed. It provides a reference for the selection of similar materials for sandstone roofing in underground gasification model experiments.

(2) In this test, the fifth group meets the theoretical requirements and can be applied to the underground coal gasification simulation experiment. The geometric similarity ratio is 30 , the density similarity ratio is 1.67 , the strength similarity ratio is 30 , and the 
compressive strength is $1.36 \mathrm{MPa}$. The mass ratio of raw materials of similar materials is sand: cement: gypsum $=6: 1: 1$

(3) The material strength is most sensitive to sand, then cement and gypsum. Cement and gypsum have a great influence on the compressive strength of similar materials. There is no non-negligible interaction between sand, cement and gypsum. The compressive strength decreases as the aggregate-binder ratio increases. When the aggregate-binder ratio remains the same, the compressive strength decreases as the cement-gypsum ratio increases.

(4) The compressive strength-elastic modulus curve of the specimen increases linearly and conforms to the sandstone fitting curve in the coal-bearing strata.

(5) The failure mode of similar materials is mainly shear failure. The main performance is as follows: the end face of the test piece penetrates through cracking, and there are one or several obvious fracture surfaces. These fracture surfaces have an angle with the central axis of the test piece, the test piece is divided into a cone shape or a triangular shape.

In addition, the main purpose of this experiment is to find a similar material ratio for compressive strength suitable for underground gasification simulation experiments. After the similar material ratio of the underground gasification model experiment is determined, the similar materials can be mechanically tested at different temperatures.

\section{References}

1. A.W. Bhutto, A.A. Bazmi, G. Zahedi, Progress in Energy and Combustion Science. J. 39:1, 189 (2013)

2. K. Stańczyk, K. Kapusta, M. Wiatowski, J. Świądrowski, A. Smoliński, J. Rogut, A. Kotyrba, Fuel. J. 91:1, 40 (2012)

3. L. Jiang, Z. Chen, S.M. Farouq Ali, Fuel. J. 224, 128 (2018)

4. J.C. Fair, O.A. Larson, H.H. Hasiba, Energy. J. 1:1, 77 (1976)

5. A. Dufaux, B. Gaveau, R. Létolle, M. Mostade, M. Noël, J.-P. Pirard, Fuel. J. 69:5, 624 (1990)

6. A. Verma, B. Olateju, A. Kumar, Energy. J. 85, 556 (2015)

7. A. Khadse, M. Qayyumi, S. Mahajani, P. Aghalayam, Energy .J. 32:11, 2061 (2007)

8. A.N. Khadse, Fuel. J. 142, 121 (2015)

9. A.A. Eftekhari, H. Van Der Kooi, H. Bruining, Energy. J. 45:1, 729 (2012)

10. F.-q. Su, A. Hamanaka, K.-i. Itakura, W. Zhang, G. Deguchi, K. Sato, K. Takahashi, J.-i. Kodama, Applied Energy. J. 223, 82 (2018)

11. M.S. Blinderman, A.Y. Klimenko, Joe Hayton. J. (2018)

12. G. Perkins, Progress in Energy and Combustion Science. J. 67, 158 (2018)

13. G. Perkins, Progress in Energy and Combustion Science. J. 67, 234 (2018)

14. M.A. Rosen, B.V. Reddy, S.J. Self, 10 - Underground coal gasification (UCG) modeling and analysis, in: M.S. Blinderman, A.Y. Klimenko (Eds.) Underground Coal Gasification and Combustion, 329-362 (Woodhead Publishing, 2018)

15. M. Wiatowski, K. Kapusta, J. Świądrowski, K. Cybulski, M. Ludwik-Pardała, J. Grabowski, K. Stańczyk, Fuel. J. 159, 454 (2015)

16. L. Yang, X. Zhang, S. Liu, L. Yu, W. Zhang, International Journal of Hydrogen Energy. J. 33:4, 1275 (2008)

17. V. Prabu, K. Geeta, Energy. J. 84, 672 (2015)

18. L. Yang, Fuel Processing Technology. J. 84:1 (3), 79 (2003) 
19. V. Prabu, S. Jayanti, Energy. J. 36:10, 5854 (2011)

20. M. Wiatowski, K. Kapusta, M. Ludwik-Pardała, K. Stańczyk, Fuel. J. 184, 401 (2016)

21. A. Chen, J. Gu, J. Shen, Q. Meiji, L. Gu, Z. Lu, Chinese Journal of Rock Mechanics and Engineering. J. 23:22, 3785 (2004)

22. W. Cheng, L. Sun, G. Wang, W. Du, H. Qu, International Journal of Mining Science and Technology. J. 26:5, 913 (2016)

23. W. Li, Y. Ge, F. Zhang, Journal of Luoyang Institute of Science and Technology (Natural Science Edition). J. 23:1, 7 (2013)

24. J. Xi, J. Liang, S. Liang, Z. Wang, Y. Duan, Coal Engineering. J. 47:5, 101 (2015)

25. M. Nieć, E. Sermet, J. Chećko, J. Górecki, Fuel. J. 208, 193 (2017)

26. J. Liu, China University of Mining. J. (2014)

27. L. Kong, J. Sun, Opencast Mining Technology. J. 4, 33 (2007)

28. T. Yin, Study on dynamic mechanical properties and failure mechanism of siltstone after high temperature (2008)

29. S. Chen, W. Guo, Y. Yang, Rock and Soil Mechanics. J. 30:9, 2595 (2009)

30. Z. Zhao, H. Xie, Journal of Sichuan University (Engineering Science Edition). J. 40:02, 26 (2008)

31. J.-F. Chen, X.-T. Wang, J.-F. Xue, Y. Zeng, S.-Z. Feng, Geotextiles and Geomembranes. J. 46:3, 277 (2018)

32. B. Lin, D. Xu, Safety in Coal Mines. J. 48:3, 160 (2017) 